\title{
The influence of alkalosis on repeated high-intensity exercise performance and acid-base balance recovery in acute moderate hypoxic conditions
}

\author{
Lewis Anthony Gough ${ }^{1,2}$ - Danny Brown ${ }^{2}$. Sanjoy K. Deb ${ }^{2}$ S. Andy Sparks² $\cdot$ Lars R. McNaughton ${ }^{2,3}$
}

Received: 12 June 2018 / Accepted: 24 August 2018 / Published online: 8 September 2018

(c) The Author(s) 2018

\begin{abstract}
Purpose Exacerbated hydrogen cation $\left(\mathrm{H}^{+}\right)$production is suggested to be a key determinant of fatigue in acute hypoxic conditions. This study, therefore, investigated the effects of $\mathrm{NaHCO}_{3}$ ingestion on repeated $4 \mathrm{~km}$ TT cycling performance and post-exercise acid-base balance recovery in acute moderate hypoxic conditions.

Methods Ten male trained cyclists completed four repeats of $2 \times 4 \mathrm{~km}$ cycling time trials $\left(\mathrm{TT}_{1}\right.$ and $\left.\mathrm{TT}_{2}\right)$ with 40 min passive recovery, each on different days. Each TT series was preceded by supplementation of one of the $0.2 \mathrm{~g} \mathrm{~kg}^{-1} \mathrm{BM} \mathrm{NaHCO}_{3}$ (SBC2), $0.3 \mathrm{~g} \mathrm{~kg}^{-1} \mathrm{BM} \mathrm{NaHCO}_{3}$ (SBC3), or a taste-matched placebo (0.07 $\mathrm{g} \mathrm{kg}^{-1} \mathrm{BM}$ sodium chloride; PLA), administered in a randomized order. Supplements were administered at a pre-determined individual time to peak capillary blood bicarbonate concentration $\left(\left[\mathrm{HCO}_{3}{ }^{-}\right]\right)$. Each TT series was also completed in a normobaric hypoxic chamber set at $14.5 \%$ $\mathrm{FiO}_{2}(\sim 3000 \mathrm{~m})$.

Results Performance was improved following SBC3 in both $\mathrm{TT}_{1}(400.2 \pm 24.1$ vs. $405.9 \pm 26.0 \mathrm{~s} ; p=0.03)$ and $\mathrm{TT}_{2}$ $(407.2 \pm 29.2$ vs. $413.2 \pm 30.8 \mathrm{~s} ; p=0.01)$ compared to PLA, displaying a very likely benefit in each bout. Compared to SBC2, a likely and possible benefit was also observed following SBC3 in $\mathrm{TT}_{1}(402.3 \pm 26.5 \mathrm{~s} ; p=0.15)$ and $\mathrm{TT}_{2}(410.3 \pm 30.8 \mathrm{~s}$; $p=0.44)$, respectively. One participant displayed an ergolytic effect following SBC3, likely because of severe gastrointestinal discomfort, as SBC2 still provided ergogenic effects.

Conclusion $\mathrm{NaHCO}_{3}$ ingestion improves repeated exercise performance in acute hypoxic conditions, although the optimal dose is likely to be $0.3 \mathrm{~g} \mathrm{~kg}^{-1} \mathrm{BM}$.
\end{abstract}

Keywords Buffers · Alkalosis · Individual pursuit $\cdot$ Personalised nutrition · Track cycling

$\begin{array}{ll}\text { Abbreviations } \\ \mathrm{Ca}^{2+} & \text { Calcium } \\ \mathrm{Cl}^{-} & \text {Chloride } \\ \mathrm{CI} & \text { Confidence intervals }\end{array}$

Communicated by Michael Lindinger.

Lewis Anthony Gough

lewis.gough@bcu.ac.uk

1 Sport and Physical Activity Department, Faculty of Health and Life Sciences, Birmingham City University, Birmingham B13 3TN, UK

2 Sports Nutrition and Performance Group, Department of Sport and Physical Activity, Edge Hill University, Ormskirk, Lancashire L39 4QP, UK

3 Department of Sport and Movement Studies, Faculty of Health Science, University of Johannesburg, Johannesburg, South Africa
$\mathrm{FiO}_{2} \quad$ Fraction of inspired oxygen

GI Gastrointestinal

$\mathrm{HCO}_{3}{ }^{-} \quad$ Bicarbonate anion concentrations

$\mathrm{H}^{+} \quad$ Hydrogen cation

$\mathrm{K}^{+} \quad$ Potassium

SID Strong ion difference

$\mathrm{VO}_{2 \max } \quad$ Maximal rate of oxygen uptake

$\mathrm{Na}^{+} \quad$ Sodium

$\mathrm{O}_{2} \quad$ Oxygen

$\mathrm{SpO}_{2} \quad$ Haemoglobin saturation of oxygen

$\mathrm{NaHCO}_{3}$ Sodium bicarbonate

$\mathrm{NaCl}$ Sodium chloride

TT Time trial 


\section{Introduction}

Repeated bouts of high-intensity exercise are a frequent feature of training and competition in athletes (Monedero and Donne 2000; Barnett 2006). The recovery between these exercise bouts is an essential component for determining the effectiveness of the subsequent bout. Enhanced recovery can allow athletes to tolerate greater training loads in the subsequent bout, potentially enhancing the post-training adaptation as a result (Barnett 2006). Whereas, in competition, enhancing recovery is an important component to sustain performance within the subsequent bout. This is applicable to sports such as track cycling, swimming, or a rowing regatta series which involve heats, semi-finals, and finals within a short amount of time (Al-Nawaiseh et al. 2016; Monedero and Donne 2000). Specifically, the gap between the men's team pursuit first round and the final at the Rio 2016 Olympics was separated by just $60 \mathrm{~min}$. Considering that most national and Olympic records are achieved within the preliminary rounds of these events (Al-Nawaiseh et al. 2016), this suggests that full recovery is not always possible during these time frames or that current recovery practices are not optimal. Therefore, interventions to improve recovery and sustain subsequent exercise performance are important.

A major factor that may hamper post-training recovery and the subsequent bout of exercise is the metabolic disturbance that occurs following an initial high-intensity exercise bout (Barnett 2006). Ward et al. (2016) reported that the decline in $\mathrm{pH}$ and $\mathrm{HCO}_{3}{ }^{-}$following a $4 \mathrm{~km}$ cycling time trial (TT; team pursuit distance) was substantial,

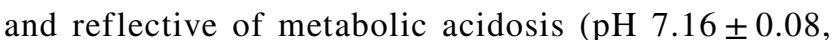
$\mathrm{HCO}_{3}{ }^{-} 11.9 \pm 2.3 \mathrm{mmol} \mathrm{l}^{-1}$ ), which was measured using capillary blood samples. Full recovery of such disturbances is likely to take over $75 \mathrm{~min}$, as Callahan et al. (2017) reported $\mathrm{HCO}_{3}{ }^{-}$was $6.2 \mathrm{mmol}^{-1}$ below baseline at this point $\left(19.5 \pm 1.4\right.$ vs. $\left.25.7 \pm 1.0 \mathrm{mmol}^{-1}\right)$. If only $60 \mathrm{~min}$ is available for recovery, therefore, such as that during track cycling events, an existing acid-base balance perturbation will be evident. Although contentious (Westerblad 2016), critical rises in hydrogen cation $\left(\mathrm{H}^{+}\right)$ accumulation are linked to a reduction in both the release and uptake of calcium ions $\left(\mathrm{Ca}^{2+}\right)$ from the sarcoplasmic reticulum (Allen et al. 2008), disruption of key enzymes of the glycolytic pathway (Hollidge-Horvat et al. 1999), and a reduction in muscle excitability and action potentials by reducing the strong ion difference (SID) (Cairns and Lindinger 2008). In turn, this may hamper subsequent performance by reducing the capability for muscle force production (Cairns 2006; Fitts 2016). It is intuitive to suggest, therefore, that interventions to accelerate post-exercise recovery of acid-base balance could be beneficial for a subsequent bout of exercise.

The ingestion of sodium bicarbonate $\left(\mathrm{NaHCO}_{3}\right)$ has been shown to accelerate post-exercise acid-base balance recovery and subsequent exercise performance (Pruscino et al. 2008; Zabala et al. 2008, 2011; Gough et al. 2017a). Pruscino et al. (2008) reported a 'trivial' to 'moderate' benefit in the second bout of a $2 \times 200 \mathrm{~m}$ freestyle swim (interspersed with a $30 \mathrm{~min}$ recovery) following pre-exercise ingestion of $\mathrm{NaHCO}_{3}$. It was then later reported that $\mathrm{NaHCO}_{3}$ ingestion $30 \mathrm{~min}$ into a $90 \mathrm{~min}$ post-exercise recovery significantly improved subsequent cycling capacity at $100 \%$ peak mean minute power by $16.6 \%$ (Gough et al. 2017a). Both studies reported that capillary blood $\mathrm{pH}$ and $\mathrm{HCO}_{3}{ }^{-}$recovery were accelerated and above baseline at the end of the recovery period, whereas the placebo condition failed to fully recover. This time frame between bouts might explain why ergogenic effects were observed, as this allowed $\mathrm{pH}$ and $\mathrm{HCO}_{3}{ }^{-}$to recover sufficiently. Conversely, no effect of $\mathrm{NaHCO}_{3}$ ingestion has been reported on three repeated Wingate tests separated shorter recovery time frames of between 15 and 30 min (Zabala et al. 2008, 2011), or during three repeated high-intensity swimming bouts separated by $20 \mathrm{~min}$ (Pierce et al. 1992). Zabala et al. (2008) showed that neither $\mathrm{pH}$, nor $\mathrm{HCO}_{3}{ }^{-}$recovered back to baseline levels between the three Wingate tests, suggesting that the recovery of $\mathrm{pH}$ and $\mathrm{HCO}_{3}{ }^{-}$to this level may be important to produce ergogenic effects in the subsequent exercise bouts.

Despite the promising effects of $\mathrm{NaHCO}_{3}$ ingestion to improve repeated bouts of exercise in normoxia, this strategy has yet to be applied to acute hypoxia. Nonetheless, Robergs et al. (2005) reported the use of $\mathrm{NaHCO}_{3}$ combined with sodium citrate lead to post-exercise recovery of $\mathrm{pH}$ and $\mathrm{HCO}_{3}{ }^{-}$to baseline in approximately $50 \mathrm{~min}$ at $1570 \mathrm{~m}$ terrestrial altitude, whereas the placebo condition failed to recover to baseline within the $80 \mathrm{~min}$ sampling period. Robergs et al. (2005) featured no subsequent bout of exercise, however, and it is also unclear if the participant cohort completed an acclimatisation period in the terrestrial altitude location. This enhanced post-exercise recovery displayed by Robergs et al. (2005) is potentially important, nonetheless, as athletes may complete multiple bouts of high-intensity exercise to maximise the adaptation from hypoxic training schedules, therefore, highlighting the need for optimal recovery. The use of pre-exercise $\mathrm{NaHCO}_{3}$ ingestion may, in turn, result in a blunting of the initial stress of acid-base balance during an initial bout of exercise, but also improve recovery, leading to improved subsequent exercise performance. This may have a cumulative effect in sustaining training volume and intensity during hypoxic training schedules, particularly considering chronic $\mathrm{NaHCO}_{3}$ ingestion has been shown to be effective at improving performance following training schedules at sea level (Egger et al. 2014; Durkalec-Michalski et al. 
2018). The aim of this study, therefore, was to investigate the effects of both $0.2 \mathrm{~g} \mathrm{~kg}^{-1} \mathrm{BM}$ and $0.3 \mathrm{~g} \mathrm{~kg}^{-1} \mathrm{BM} \mathrm{NaHCO}_{3}$ on repeated bouts of $4 \mathrm{~km}$ TT cycling performance in acute moderate hypoxic conditions. The hypothesis of this study was that both doses of $\mathrm{NaHCO}_{3}$ would improve both bouts of exercise compared to the placebo; however, $0.3 \mathrm{~g} \mathrm{~kg}^{-1} \mathrm{BM}$ $\mathrm{NaHCO}_{3}$ would improve performance to the greatest extent.

\section{Methods}

\section{Participants and compliance with ethical standards}

Ten trained male cyclists (age $27 \pm 8$ years, body mass $82 \pm 9 \mathrm{~kg}$, hypoxic maximal rate of oxygen uptake $\left(V \mathrm{O}_{2 \max }\right)$

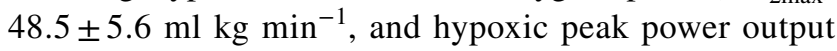
$331 \pm 40 \mathrm{~W}$ ) volunteered for this study. All participants' training load was reflective of a 'trained' cyclist (De Pauw et al. 2013). Ethical approval was granted from the Universities Research Ethics Committee (URESC16-LG01; Edge Hill University), and all participants provided written informed consent.

\section{Experimental overview}

Using methods previously described (Gough et al. 2017b), an initial maximal rate of oxygen uptake $\left(V \mathrm{O}_{2 \max }\right)$ test was conducted in a normobaric hypoxic chamber set at a fraction of inspired oxygen $\left(\mathrm{FiO}_{2}\right)$ of $14.5 \%(\sim 3000 \mathrm{~m})$. Participants then visited the laboratory on a further six separate occasions in a block randomized, crossover, and double-blind designed study $\left(2 \times\right.$ identification of peak blood $\mathrm{HCO}_{3}{ }^{-}$, and $4 \times$ cycling TTs). Individual time to peak $\mathrm{HCO}_{3}{ }^{-}$was determined prior to the cycling time trials, using a previously described method (Gough et al. 2017c). This entailed participants ingesting either $0.2 \mathrm{~g} \mathrm{~kg}^{-1} \mathrm{BM} \mathrm{NaHCO}_{3}(\mathrm{SBC} 2)$ or $0.3 \mathrm{~g} \mathrm{~kg}^{-1} \mathrm{BM} \mathrm{NaHCO}{ }_{3}$ (SBC3) on separate occasions, followed by a quiet rest for $180 \mathrm{~min}$. Finger prick capillary blood samples were taken every $10 \mathrm{~min}$, and the highest value of $\mathrm{HCO}_{3}{ }^{-}$was then used as the individual time to peak. Twenty-four hours prior to each cycling TT, participants refrained from consumption of alcohol and caffeine, any strenuous activity, and maintenance of nutritional intake, which was confirmed via use of written nutrition/training diaries. Finally, participants were verbally screened to ensure avoidance of beta alanine ingestion had not occurred prior to enrolment onto the study, to account for the long washout of carnosine (Baguet et al. 2009).

\section{Time trial protocol, supplementation of sodium bicarbonate, and blood measures}

Participants completed $2 \times 4 \mathrm{~km}$ TTs $\left(\mathrm{TT}_{1}\right.$ and $\left.\mathrm{TT}_{2}\right)$ interspersed with a $40 \mathrm{~min}$ recovery. The protocols for the TT, including the self-selected warm-up, were identical to those detailed in the previous research (Gough et al. 2017c), whereby only cadence and gear was displayed to the participant. Each TT series was preceded by supplementation of one of the SBC2, SBC3, or a taste-matched placebo ( $0.07 \mathrm{~g} \mathrm{~kg}^{-1} \mathrm{BM}$ sodium chloride; PLA) administered in a block-randomized order. The randomisation of supplements was carried out by an individual who was not involved in the research, and performance times remained double-blind until completion of the study. Participants remained seated until their respective pre-determined time to peak $\mathrm{HCO}_{3}{ }^{-}$in normoxic conditions. Once reached, participants then entered the normobaric hypoxic chamber $\left(\mathrm{FiO}_{2} 14.5 \%\right)$ for $10 \mathrm{~min}$, prior to beginning the $\mathrm{TT}_{1}$ warm-up. Following $\mathrm{TT}_{1}$, participants completed a passive recovery entailing a quiet seated rest for $40 \mathrm{~min}$ within the hypoxic environment. Finger prick capillary blood samples for acid-base balance $\left(\mathrm{pH}\right.$ and $\left.\mathrm{HCO}_{3}{ }^{-}\right)$, electrolytes $\left(\mathrm{K}^{+}, \mathrm{Na}^{+}, \mathrm{Ca}^{2+}\right.$, and $\left.\mathrm{Cl}^{-}\right)$, lactate, and haemoglobin saturation with oxygen $\left(\mathrm{SpO}_{2}\right)$ were recorded pre-exercise, at time to peak $\mathrm{HCO}_{3}{ }^{-}$, immediately postexercise and at $10 \mathrm{~min}$ intervals during the $40 \mathrm{~min}$ passive recovery. These blood samples were immediately analysed using a reliable blood gas analyser (ABL800BASIC, Radiometer Medical ltd., Denmark), apart from lactate, which was analysed using a reliable and accurate lactate pro 2 analyser (Arkray, Japan) (Pyne et al. 2000; Bonaventura et al. 2015). To maintain the double-blind nature of the study, the screen on the blood gas analyser was covered, and an individual who was not part of the research stored the data until completion of the study. Calculation of the apparent SID was conducted using the formula $\left(\left[\mathrm{K}^{+}\right]+\left[\mathrm{Na}^{+}\right]+\left[\mathrm{Ca}^{2+}\right]+\left[\mathrm{Na}^{+}\right]-\left[\mathrm{Cl}^{-}\right]-\left[\mathrm{Lac}^{-}\right]\right)$ (Lloyd 2004). Afterwards, participants completed the $\mathrm{TT}_{2}$ warm-up, followed by $\mathrm{TT}_{2}$. Additional blood samples were obtained following the warm-up in $\mathrm{TT}_{2}$ and immediately post $\mathrm{TT}_{2}$ for the same measures previously described.

\section{Perceptual measures}

Rating of perceived exertion for overall body exertion $\left(\mathrm{RPE}_{\mathrm{O}}\right)$ and the legs $\left(\mathrm{RPE}_{\mathrm{L}}\right)$ was recorded during $\mathrm{TT}_{1}$ and $\mathrm{TT}_{2}$ every $1 \mathrm{~km}$, whilst $\mathrm{HR}$ and $\mathrm{SPO}_{2}$ were recorded during both $\mathrm{TT}_{1}$ and $\mathrm{TT}_{2}$ at every $500 \mathrm{~m}$ split and at $10 \mathrm{~min}$ intervals during recovery. Gastrointestinal (GI) discomfort was recorded at 10 min intervals after ingestion of the supplement (i.e., SBC2, SBC3, or PLA) up to the 
individual time to peak $\mathrm{HCO}_{3}{ }^{-}$, and at 10 min intervals during the 40 min recovery. At individual time to peak $\mathrm{HCO}_{3}{ }^{-}$, participants were asked if they could determine which supplement they had ingested using a supplement belief questionnaire.

\section{Statistical analysis}

No evidence of a violation for normality and sphericity was evident in any assessed variable, and therefore, the appropriate parametric statistical tests were employed. A paired $t$ test was conducted for the following: both the time to peak and absolute change in $\mathrm{pH}$ and $\mathrm{HCO}_{3}{ }^{-}$, and both the severity and aggregated score for GI discomfort following SBC treatments. Performance data (time to TT completion and mean power) and blood parameters (change in $\mathrm{pH}$ and $\mathrm{HCO}_{3}{ }^{-}$during $\mathrm{TT}_{1}$, recovery, and $\mathrm{TT}_{2}$ ) were analysed using a repeated measures ANOVA. In addition, magnitude-based inferences (MBI) with 90\% confidence intervals (CI) were calculated for performance data and interpreted using an adapted method from a freely available spreadsheet (Batterham and Hopkins 2006). The thresholds to depict a benefit or harm were set as the typical error of the $4 \mathrm{~km}$ TT when converted from a percentage to an absolute value. This was completed by calculating the difference score in each individual, then calculating the standard deviation of the difference scores, and finally by dividing this by $\sqrt{ } 2$ (Swinton et al. 2018). This was used as in many cases, the 0.2 small effect size of Cohen $d$ (Cohen 1988) is less than the typical error and, therefore, produces inflated positive results. Otherwise, a two-way [treatment $\times$ time] repeated measures ANOVA was conducted with a Bonferroni correction. Effect size for interactions is reported as partial eta squared $\left(\mathrm{P} \eta^{2}\right)$ and where appropriate, between treatment Hedge's $g$ effect sizes $(g)$ are reported and interpreted as per conventional thresholds (Cohen 1988). Significant effects are displayed with 95\% CI where appropriate. Reproducibility of the absolute changes in $\mathrm{pH}$ and $\mathrm{HCO}_{3}{ }^{-}$in the preliminary trial and the subsequent cycling trials was assessed using intraclass correlation coefficients (ICC). Data are reported as mean \pm standard deviation (SD) and statistical significance was set at $p<0.05$. Data were analysed using a statistical software package, SPSS (V.22, IBM Inc., Chicago, IL, USA).

\section{Results}

\section{Preliminary trials to determine time to peak blood bicarbonate}

Time to peak $\mathrm{pH}$ ranged between 30 and $100 \mathrm{~min}$ in $\mathrm{SBC} 2$ (mean $66 \pm 22 \mathrm{~min}$; median $60 \mathrm{~min}$; CV 34\%) and between 40 and 120 min in SBC3 (mean $76 \pm 21 \mathrm{~min}$; median $75 \mathrm{~min}$;
CV 27\%; $p=0.04)$. The absolute change from baseline to peak $\mathrm{pH}$ was similar in SBC2 and SBC3 $(0.08 \pm 0.02$ vs. $0.09 \pm 0.02 ; p=0.27)$. In the subsequent cycling trials, the reproducibility of the absolute change in $\mathrm{pH}$ was fair in SBC2 $(r=0.50, p=0.09)$ and good in SBC3 $(r=0.60$, $p=0.06)$. Time to peak $\mathrm{HCO}_{3}{ }^{-}$was achieved between 30 and 110 min in SBC2 (mean $67 \pm 21$ min; median 60 min; CV 31\%) compared to between 50 and $100 \mathrm{~min}$ in SBC3 (mean $77 \pm 17$ min; median $75 \mathrm{~min} ; \mathrm{CV} 22 \% ; p=0.20$ ). The absolute change from baseline was greater $\left(+1 \mathrm{mmol} \mathrm{l}^{-1}\right)$ in SBC3 compared to SBC2 (7.1 \pm 1.2 vs. $6.0 \pm 0.9 \mathrm{mmol}^{-1}$; $p=0.04 ; g=1.0$ ). In the subsequent cycling trials, the reproducibility of the change from baseline to peak $\mathrm{HCO}_{3}{ }^{-}$was good in SBC2 $(r=0.70, p=0.04)$ and excellent in SBC3 $(r=0.77, p=0.02)$.

\section{Performance}

The decline in performance from $\mathrm{TT}_{1}$ to $\mathrm{TT}_{2}$ was similar in all treatments $(\mathrm{SBC} 28.0 \pm 6.8$ vs. $\mathrm{SBC} 37.0 \pm 6.3$ vs. PLA $7.3 \pm 6.4 \mathrm{~s} ; p>0.05)$. In $\mathrm{TT}_{1}, \mathrm{SBC}_{3}$ improved performance compared to PLA by $1.4 \pm 1.5 \%(400.2 \pm 24.1$ vs. $405.9 \pm 26.0 \mathrm{~s} ; p=0.03 ; \mathrm{CI}=10.6,0.8 ; g=0.2$; Fig. 1 ), which was determined as a very likely benefit in MBI analysis. Meanwhile, SBC2 displayed a likely benefit compared to PLA, improving performance by $0.9 \pm 1.1 \%(402.3 \pm 26.5 \mathrm{~s}$; $p=0.14 ; g=0.1$; Fig. 1 . A likely benefit was also observed in SBC3 vs. SBC2 $(p=0.15 ; g=0.1)$. Findings were similar in $\mathrm{TT}_{2}$, where $\mathrm{SBC} 3$ again displayed the fastest completion times by $1.4 \pm 1.1 \%$ compared to PLA ( $407.2 \pm 29.2$ vs. $413.2 \pm 30.8 \mathrm{~s} ; p=0.01 ; \mathrm{CI}=10.5,1.5 ; g=0.2)$, which MBI analysis determined this as a very likely effect. Whereas, SBC2 improved performance by $0.7 \pm 1.2 \%$ compared to PLA $(410.3 \pm 30.8 \mathrm{~s})$ and this was determined as a likely benefit ( $p=0.35 ; g=0.1$; Fig. 2 ). A possible benefit was determined for $\mathrm{SBC} 3$ compared to $\mathrm{SBC} 2$ for $\mathrm{TT}_{2}$ completion time $(p=0.44 ; g=0.1)$.

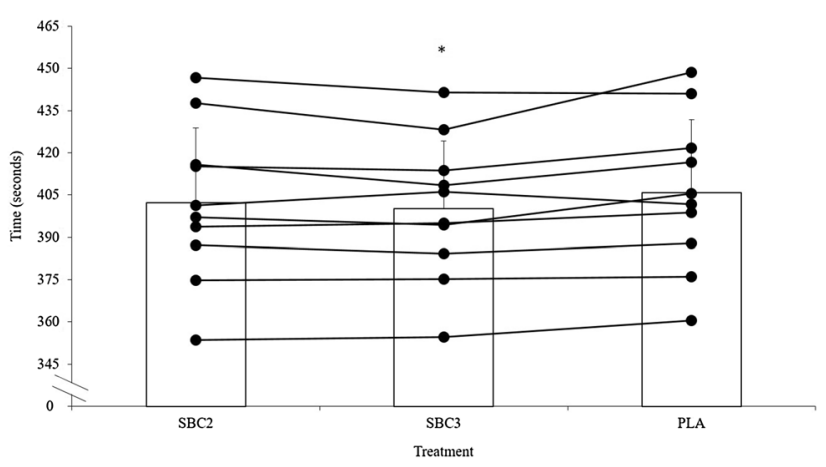

Fig. 1 Mean $( \pm \mathrm{SD})$ and individual (horizontal lines) time to complete time trial $1\left(\mathrm{TT}_{1}\right)$ following $\mathrm{SBC} 2, \mathrm{SBC} 3$, and PLA. Asterisk denotes significantly improved compared to PLA $(p<0.05)$ 


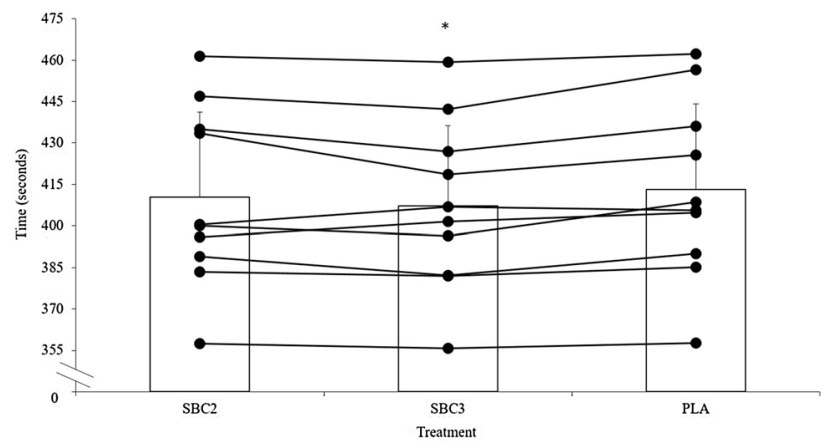

Fig. 2 Mean $( \pm \mathrm{SD})$ and individual (horizontal lines) time to complete time trial $2\left(\mathrm{TT}_{2}\right)$ following SBC and PLA treatments. Asterisk denotes significantly improved compared to PLA $(p<0.05)$

Mean power in $\mathrm{TT}_{1}$ was $4.1 \%$ greater in $\mathrm{SBC} 3$ compared to PLA $(247 \pm 41$ vs. $258 \pm 41 ; p=0.03$; CI $=1.7,19.6$; $g=0.3$ ), showing a very likely improvement. Meanwhile, SBC2 improved mean power by $2.5 \%$ compared to PLA, also revealing a very likely benefit (vs. $254 \pm 43 \mathrm{~W} ; p=0.68$; $g=0.2$ ). A likely benefit was determined for SBC3 vs. SBC2 $(p=0.39 ; g=0.1)$. Mean power in $\mathrm{TT}_{2}$ was improved by $3.8 \%$ in SBC3 compared to PLA ( $247 \pm 46$ vs. $237 \pm 47 \mathrm{~W}$; $p=0.005 ; \mathrm{CI}=3.0,15.5 ; g=0.2)$, and demonstrated a most likely benefit. Whereas, a likely benefit was determined in SBC2 (vs. $242 \pm 47 \mathrm{~W} ; p=0.34 ; g=0.1$ ). A likely benefit was determined for SBC3 vs. SBC2 $(p=0.48 ; g=0.1)$.

\section{Blood responses}

A [treatment $\times$ time] interaction was observed for $\mathrm{HCO}_{3}{ }^{-}\left(\mathrm{P} \eta^{2}=0.65, p<0.001\right)$, as $\mathrm{HCO}_{3}{ }^{-}$was greater postsupplementation of $\mathrm{NaHCO}_{3}$ in $\mathrm{SBC} 3$ compared to both SBC2 $(p=0.02 ; \mathrm{CI}=0.3,2.5, g=1.5)$ and PLA $(p<0.001$; $\mathrm{CI}=6.3,7.9 ; g=8.4$; Fig. 3$)$. Whereas, $\mathrm{SBC} 2$ was greater than PLA only $(p<0.001 ; \mathrm{CI}=4.4,7.1 ; g=5.7)$. Post $\mathrm{TT}_{1}$, $\mathrm{HCO}_{3}{ }^{-}$was greater in both $\mathrm{SBC} 2$ and $\mathrm{SBC} 3$ compared to PLA (both $p<0.001$ ), with no differences between SBC conditions $(p=0.38)$. There was a [treatment] effect for $\mathrm{HCO}_{3}{ }^{-}$change during $\mathrm{TT}_{1}\left(\mathrm{P}^{2}=0.69, p<0.001\right)$, whereby both SBC2 and SBC3 were greater than PLA $(p<0.005)$, with a small effect size between SBC treatments $(10.6 \pm 3.4$ vs. $\left.11.5 \pm 3.2 \mathrm{mmol} \mathrm{l}^{-1} ; p=0.63 ; g=0.26\right)$. A significant [treatment $\times$ time] interaction was observed for $\mathrm{pH}$ $\left(\mathrm{P} \eta^{2}=0.36, p=0.002\right)$, as $\mathrm{pH}$ was greater post-supplementation and post-TT ${ }_{1}$ warm-up in SBC3 compared to both SBC2 and PLA (both $p<0.01$ ), whilst SBC2 was greater compared to PLA $(p<0.001)$. Blood lactate was greater post-TT ${ }_{1}$ in both SBC treatments compared to PLA $(p<0.005)$, with no differences observed otherwise (all $p>0.05$; Fig. 3 ).

Both SBC treatments elicited reductions in $\mathrm{K}^{+}, \mathrm{Ca}^{2+}$, and $\mathrm{Cl}^{-}$, and increases in $\mathrm{Na}^{+}$compared to PLA (Fig. 4). The

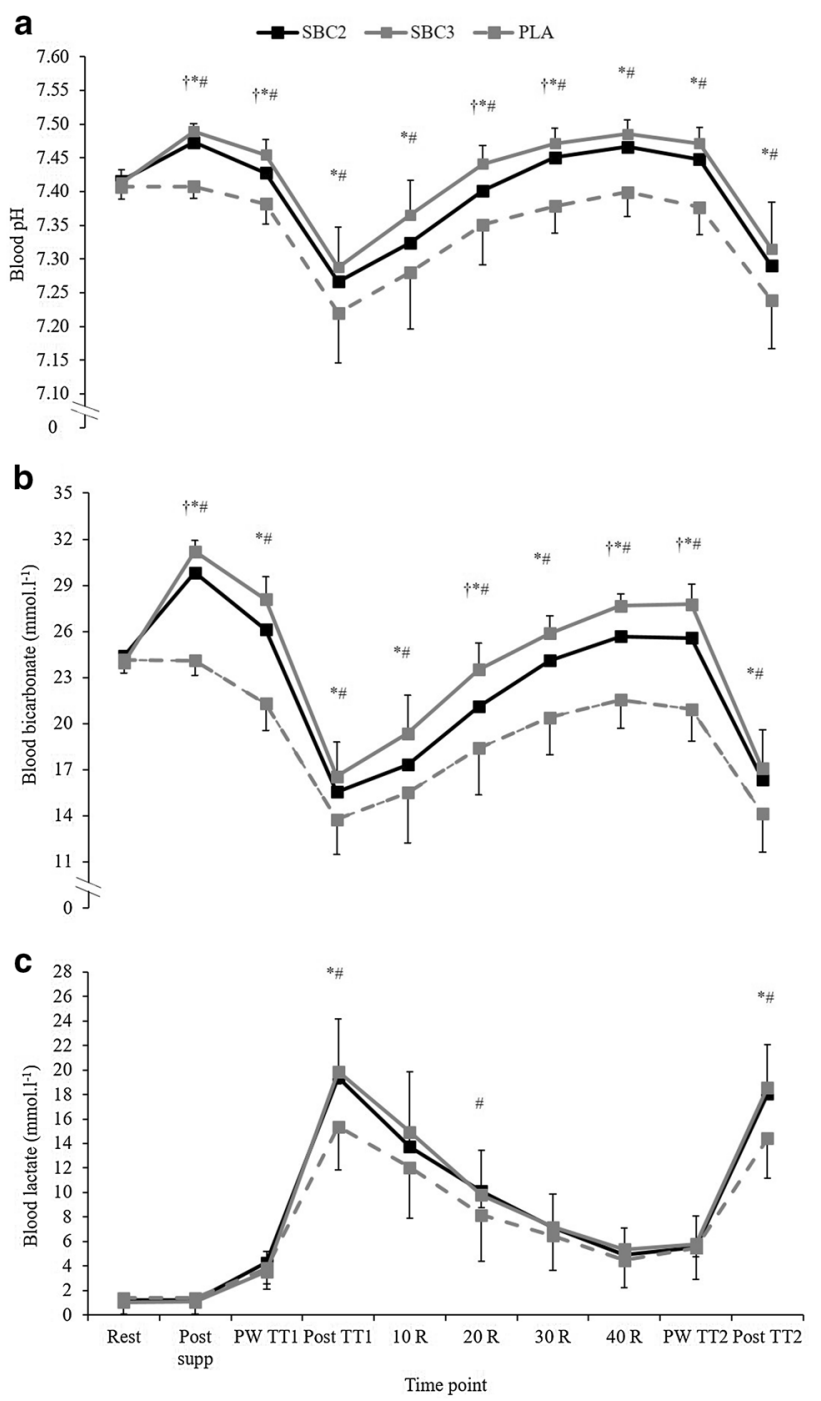

Fig. 3 Mean $( \pm \mathrm{SD})$ responses for blood a $\mathrm{pH}, \mathbf{b}$ bicarbonate $\left(\mathrm{HCO}_{3}{ }^{-}\right)$, and $\mathbf{c}$ lactate following $\mathrm{NaHCO}_{3}$ across time. SBC3 (asterisk) and SBC2 (hash symbol) significantly greater than PLA. SBC3 (dagger symbol) significantly greater than SBC2 $(p<0.05) . R$ recovery, $P W$ post warm-up

SID at post-TT ${ }_{1}$ warm-up and post-TT ${ }_{1}$ was greater in both SBC treatments compared to PLA $(p<0.005)$. However, the $\mathrm{SID}$ in $\mathrm{SBC} 3$ was greater than $\mathrm{SBC} 2$ post- $\mathrm{NaHCO}_{3}$ supplementation $(p=0.005 ; \mathrm{CI}=0.7,3.5 ; g=1.0)$ and post-TT 1 warm-up ( $p=0.049 ; \mathrm{CI}=0.01,3.6 ; g=0.8$; Fig. 5). During recovery, $\mathrm{HCO}_{3}{ }^{-}$was greater following $\mathrm{SBC} 3$ compared to PLA at all recovery timepoints $(p<0.01)$, however, only greater at $20\left(23.5 \pm 1.7 \mathrm{mmol}^{-1} ; 21.1 \pm 2.7 \mathrm{mmol}^{-1}\right.$; $p=0.04 ; \mathrm{CI}=0.2,4.7 ; g=1.0)$ and $40 \min (27.7 \pm 0.8$ vs. $\left.25.7 \pm 1.3 \mathrm{mmol} \mathrm{l}^{-1} ; p=0.006 ; \mathrm{CI}=0.6,3.3 ; g=1.8\right) \mathrm{com}$ pared to SBC2. Similarly, SBC2 was greater than PLA at all recovery timepoints (all $p<0.01$ ). The absolute change in $\mathrm{HCO}_{3}{ }^{-}$from post $\mathrm{TT}_{1}$ to 40 min recovery was significantly greater compared to PLA $\left(5.0 \pm 1.5 \mathrm{mmol}^{-1}\right)$ in both SBC2 


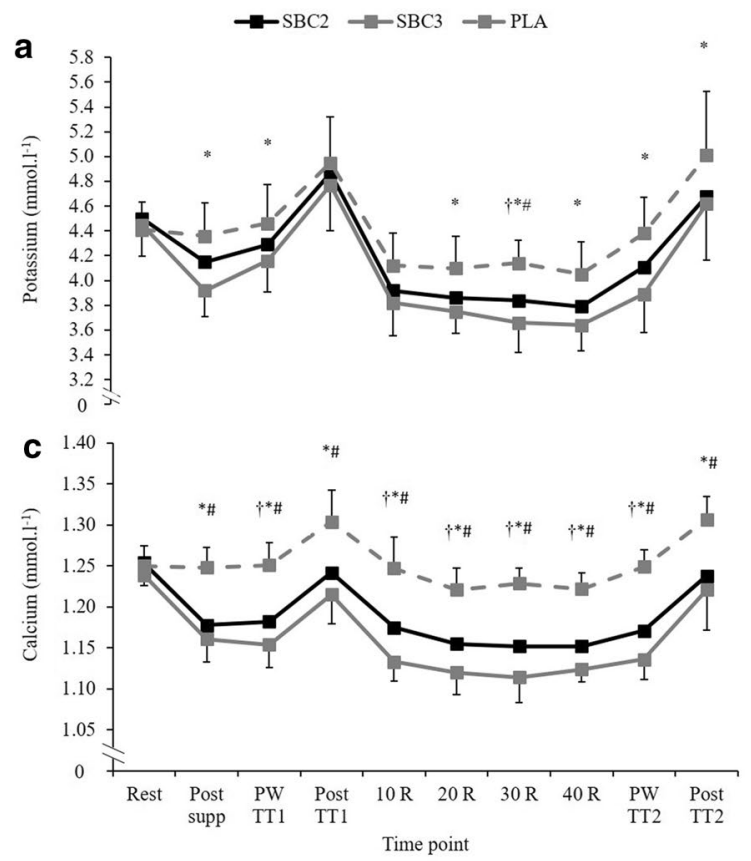

Fig. 4 Mean ( \pm SD) potassium (a), sodium (b), calcium (c), and chloride (d) responses over time following SBC treatments. SBC3 (asterisk) and SBC2 (hash symbol) significantly different compared

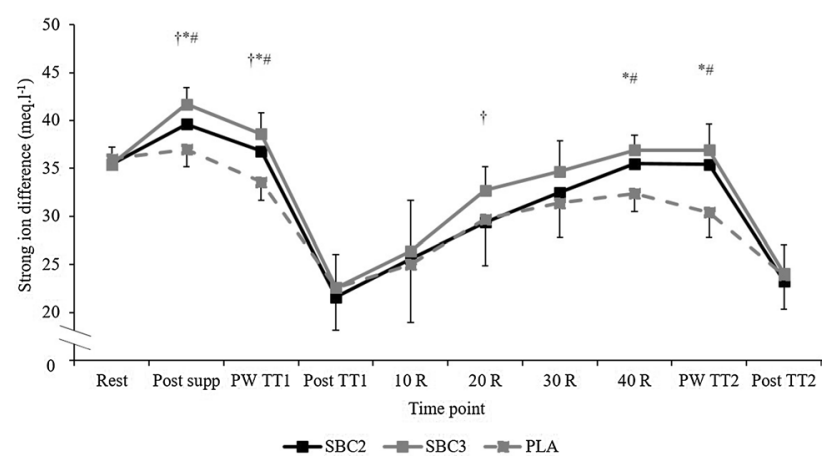

Fig. 5 Mean $( \pm S D)$ strong ion difference (SID) responses over time following SBC treatments. SBC3 (asterisk) and SBC2 (hash symbol) significantly greater than PLA. SBC3 (dagger symbol) significantly greater than SBC2 $(p<0.05)$. $R$ recovery, $P W$ post warm-up

$\left(10.1 \pm 1.4 \mathrm{mmol}^{-1}, p<0.001 ; \mathrm{CI}=3.2,7.1 ; g=3.4\right)$ and SBC3 $\left(11.1 \pm 2.5 \mathrm{mmol}^{-1}, p<0.001 ; \mathrm{CI}=4.2,8.1 ; g=2.8\right)$, with a small effect size between SBC treatments $(p=0.45$; $g=0.3)$. The absolute change in the SID from post-TT 1 to 40 min recovery was only significantly greater for SBC3 compared to PLA $(p=0.05 ; \mathrm{CI}=0.01,9.0 ; g=1.2)$.

Post warm-up in $\mathrm{TT}_{2}, \mathrm{HCO}_{3}{ }^{-}$was greater in both $\mathrm{SBC} 2$ and SBC3 compared to PLA $(p<0.001)$; however, SBC3 was greater than any treatment $(p<0.001)$. There was a [treatment] effect for $\mathrm{HCO}_{3}{ }^{-}$change during $\mathrm{TT}_{2}\left(\mathrm{P}^{2}=0.71\right.$, $p<0.001$ ), whereby both SBC treatments were greater than

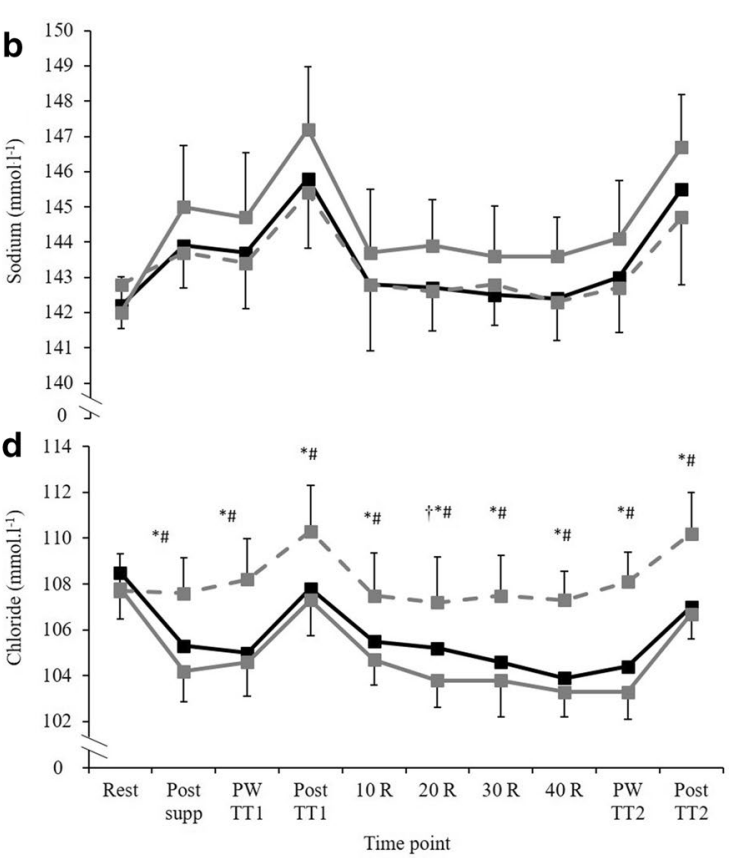

to PLA. SBC3 (dagger symbol) significantly different compared to $\mathrm{SBC} 2(p<0.05) . R$ recovery, $P W$ post warm-up

PLA $(p<0.01)$; however, SBC3 was greater compared to SBC2 $\left(10.7 \pm 2.9\right.$ vs. $9.2 \pm 2.7 \mathrm{mmol}^{-1} ; p=0.02 ; \mathrm{CI}=0.3$, 2.6; $g=0.5$; Fig. 3). Post-TT 2 warm-up, and post-TT 2 , $\mathrm{pH}$ in both SBC2 and SBC3 were greater than PLA $(p<0.001)$, although no differences between SBC treatments were observed $(p>0.05)$. Blood lactate was greater post-TT 2 in both SBC2 $\left(18.0 \pm 4.2\right.$ vs. $14.4 \pm 3.3 \mathrm{mmol} \mathrm{l}^{-1} ; p=0.05$; $\mathrm{CI}=-0.01,7.2 ; g=0.9)$ and SBC3 $\left(18.6 \pm 3.5 \mathrm{mmol} \mathrm{l}^{-1}\right.$; $p=0.009 ; \mathrm{CI}=1.1,7.2 ; g=0.9)$ compared to PLA, with no difference between SBC treatments $(p=0.424 ; g=1.2)$. Post$\mathrm{TT}_{2}$ warm-up, the SID was greater for both SBC2 and SBC3 compared to PLA $(p<0.001)$; however, no difference was observed between SBC treatments (SBC2 $35 \pm 3$ vs. SBC3 $37 \pm 3 \mathrm{meq} / \mathrm{L} ; p=0.20 ; g=0.6$ ).

\section{Perceptual responses}

During $\mathrm{TT}_{1}, \mathrm{NaHCO}_{3}$ did not affect $\mathrm{RPE}_{\mathrm{O}}\left(\mathrm{P} \eta^{2}=0.24\right.$, $p=0.07)$ or $\mathrm{RPE}_{\mathrm{L}}\left(\mathrm{P} \eta^{2}=0.10, p=0.38\right), \mathrm{HR}\left(\mathrm{P} \eta^{2}=0.07\right.$, $p=0.63)$, or $\mathrm{SPO}_{2}\left(\mathrm{P}^{2}=0.18, p=0.16\right)$. Similarly, in $\mathrm{TT}_{2}$, no changes in $\mathrm{RPE}_{\mathrm{O}}\left(\mathrm{P}^{2}=0.17, p=0.12\right), \mathrm{RPE}_{\mathrm{L}}\left(\mathrm{P}^{2}=0.11\right.$, $p=0.35)$, HR $\left(\mathrm{P}^{2}=0.07, p=0.78\right)$, or $\mathrm{SPO}_{2}\left(\mathrm{P}^{2}=0.02\right.$, $p=0.83$ ) were observed.

\section{Gastrointestinal (GI) discomfort}

In total, 6/10 (60\%) participants suffered from GI discomfort in SBC2, whereas 9/10 (90\%) suffered from GI discomfort 

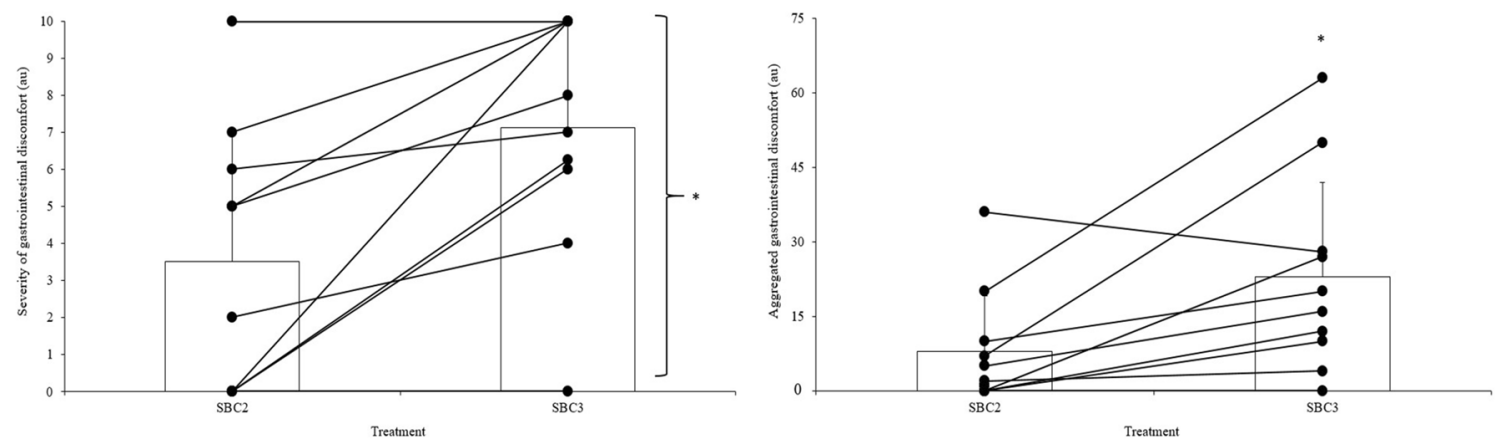

Fig. 6 Individual aggregated score and severity of gastrointestinal (GI) responses following SBC treatments. Asterisk denotes SBC3 significantly greater than SBC2 $(p<0.05)$

in SBC3. The most common GI discomfort symptom was belching (2/10) in SBC2, whilst in SBC3, diarrhoea, bowel urgency, and feeling of vomiting were most common (5/10). Both the aggregated GI discomfort and the severity of the most severe GI discomfort symptom suffered were greater in SBC3 compared to SBC2 (both $p<0.05$, Fig. 6). On $3 / 30$ $(10 \%)$ occasions, the supplement was correctly identified by the participant.

\section{Discussion}

This study investigated the effects of $\mathrm{NaHCO}_{3}$ ingestion on post-exercise acid-base balance recovery and repeated $4 \mathrm{~km}$ TT performance in moderate acute hypoxic conditions. Both SBC2 and SBC3 improved $\mathrm{TT}_{1}$ and $\mathrm{TT}_{2}$ performance compared to PLA, displaying 'likely' and 'very likely' beneficial effects in magnitude-based inferences analysis, respectively. The current study findings suggest that this occurred due to the greater magnitude of acid-base balance recovery between $\mathrm{TT}_{1}$ and $\mathrm{TT}_{2}$ or that the initial acid-base balance stress during $\mathrm{TT}_{1}$ was blunted by $\mathrm{NaHCO}_{3}$ ingestion. A greater magnitude of performance improvement was observed in SBC3, however, showing 'likely' and 'possibly' beneficial effects in $\mathrm{TT}_{1}$ and $\mathrm{TT}_{2}$ compared to $\mathrm{SBC} 2$, respectively. As such, $\mathrm{SBC} 3$ is the most optimal to improve repeated efforts of high-intensity exercise in acute moderate hypoxic conditions. One individual did display an ergolytic effect following SBC3, however, despite still gaining ergogenic effects from SBC2 vs. PLA, possibly caused by the onset of severe GI discomfort (Saunders et al. 2014). Individuals who display similar responses may, therefore, wish to select SBC2.

The current study findings suggest the enhanced exercise performance in both bouts of exercise following $\mathrm{NaHCO}_{3}$ ingestion occurred due to the combination of the greater alkalotic state of the acid-base balance prior to $\mathrm{TT}_{1}$ and the greater magnitude of acid-base balance recovery prior to $\mathrm{TT}_{2}$. The change in $\mathrm{HCO}_{3}{ }^{-}$during $\mathrm{TT}_{1}$ was increased following $\mathrm{NaHCO}_{3}(\mathrm{SBC} 2+29 \%, \mathrm{SBC} 3+34 \%)$, whilst post $\mathrm{TT}_{1}$, blood lactate was also greater compared to PLA $(\mathrm{SBC} 2+21 \%, \mathrm{SBC} 3+23 \%)$. These changes suggest an increased $\mathrm{H}^{+}$buffering from intramuscular to extracellular compartments, which may lead to an increased anaerobic energy provision and glycogen utilization, as intramuscular $\mathrm{pH}$ is better protected (Lopes-Silva et al. 2018; Percival et al. 2015). It is argued that these indirect biomarkers of upregulated glycolytic flux in the present study instead show a reduction in lactate by inactive tissue however, as the samples in the present study do provide data on use/ uptake (Granier et al. 1996). Likewise, it is strongly argued that acidosis does not inhibit contractile machinery and that alkalization may cause instability of the buffering systems, and thus, the benefit to the ATP-generating process is either negligible, or actually harmful (Korzeniewski and Zoladz 2002; Sahlin et al. 1998). A recent study by Lopes-Silva et al. (2018), nonetheless, reported similar post-exercise $\mathrm{HCO}_{3}{ }^{-}$and lactate responses to the current study following $\mathrm{NaHCO}_{3}$ ingestion, yet also reported both a $34 \%$ greater estimated glycolytic energy contribution to exercise and an improved performance. It is alternately conceivable that the increases in $\mathrm{HCO}_{3}{ }^{-}$and $\mathrm{CO}_{2}$ following $\mathrm{NaHCO}_{3}$ ingestion are part of a causal sequence of the primary mechanism of performance, by accelerating $V \mathrm{O}_{2}$ kinetics at the onset of high-power outputs (Zoladz et al. 2005). Unfortunately, $V \mathrm{O}_{2}$ was not measured during the TTs in the study, so this cannot be concluded and thus warrants further research. The current study findings, nonetheless, further support past research (Fitts 2016) that acid-base balance disturbances are an important determinant of fatigue during high-intensity exercise.

The current study adds that $\mathrm{NaHCO}_{3}$ ingestion increased the SID prior to each TT bout, which may explain the improved performance. The SID has been suggested to be an important component of action potentials by increasing muscle excitability (Allen et al. 2008). Notable changes 
$\mathrm{NaHCO}_{3}$ ingestion elicits include a lowering of extracellular $\mathrm{K}^{+}$and $\mathrm{Cl}^{-}$, whilst increasing $\mathrm{Na}^{+}$, all of which have collectively been identified to be important for muscle contraction during high-intensity exercise previously (Cairns and Lindinger 2008). Here, the current study findings expand upon those of Sostaric et al. (2006) that reported an improvement in finger flexion to exhaustion combined with an increased SID following $\mathrm{NaHCO}_{3}$ ingestion, by showing a similar effect but during dynamic whole-body exercise. These findings also provide an alternative mechanism to the $\mathrm{pH}$ and $\mathrm{HCO}_{3}{ }^{-}$-mediated mechanisms often criticised in the literature (Westerblad 2016). It is worth noting that the highlighted changes in the SID may also have further reaching benefits to health-related outcomes. Mild metabolic acidosis has been linked with multiple health-related outcomes including protein metabolism, by decreasing synthesis through increases of non-enzymatic proteolysis (Wiederkehr and Krapf 2001). Likewise, regular consumption of alkaline rich supplements has been shown to improve mineral balance and rate of bone formation (Sebastian et al. 1994). Therefore, more research is required investigating the use of chronic $\mathrm{NaHCO}_{3}$ ingestion in sporting populations that could also be prone to such issues, particularly endurance runners and adolescent athletes (Tenforde et al. 2017; Scofield and Hecht 2012).

Both $\mathrm{pH}$ and $\mathrm{HCO}_{3}{ }^{-}$following $\mathrm{SBC}$ treatments were increased prior to $\mathrm{TT}_{2}$, such that the absolute change in $\mathrm{HCO}_{3}{ }^{-}$from $\mathrm{TT}_{1}$ to 40 min recovery was over twofold greater compared to PLA ( $\mathrm{SBC} 2+51 \%, \mathrm{SBC} 3+55 \%)$, whilst the change in the SID was also more superior $(\mathrm{SBC} 2+29 \%, \mathrm{SBC} 3+31 \%)$. This suggests a greater amount of $\mathrm{H}^{+}$buffering occurred during this time, which subsequently facilitated a more substantial recovery of acid-base balance compared to PLA, in support of previous research (Pruscino et al. 2008; Gough et al. 2017a). Alternatively, the improvement in $\mathrm{TT}_{2}$ may have been due to the stress on acid-base balance being blunted by $\mathrm{NaHCO}_{3}$ during $\mathrm{TT}_{1}$, as $\mathrm{pH}, \mathrm{HCO}_{3}{ }^{-}$, and the SID were all greater immediately post $\mathrm{TT}_{1}$ compared to PLA. Based on data from Gough et al. (2017a), however, it is more likely that the enhancement of the acid-base balance state between $\mathrm{TT}_{1}$ and $\mathrm{TT}_{2}$ explains the improvement in the current study, as the authors reported $\mathrm{NaHCO}_{3}$ ingestion improved a subsequent exercise even when supplementation was after an initial bout of exercise. Moreover, SBC3 elicited a significantly greater magnitude of acid-base balance recovery prior to $\mathrm{TT}_{2}$, and change in $\mathrm{HCO}_{3}{ }^{-}$during $\mathrm{TT}_{2}$ compared to $\mathrm{SBC} 2$. Correspondingly, SBC3 improved performance within half of the sample compared to SBC2, compared to only two displaying greater improvements in SBC2 vs. SBC3 when using the $3.1 \mathrm{~s} \mathrm{TE}$ of the test. Combined, these greater increases in acid-base balance blood analytes may explain the greater magnitude of improvement in $\mathrm{TT}_{2}$ produced by $\mathrm{SBC} 3$.
At $40 \mathrm{~min}$ recovery $\mathrm{pH}, \mathrm{HCO}_{3}{ }^{-}$and the SID were still rising following $\mathrm{NaHCO}_{3}$ ingestion, such that $\mathrm{pH}$ at 40 min recovery was $7.49 \pm 0.02$ in SBC3, which was identical to the increase prior to $\mathrm{TT}_{1}$ following the same dose $(7.49 \pm 0.01)$. This is in agreement with the previous research in normoxia showing similar increases at the end of a recovery period typically seen with pre-exercise $\mathrm{NaHCO}_{3}$ ingestion (Callaghan et al. 2017; Pruscino et al. 2008). Equally, in the current study, and others (Callaghan et al. 2017; Pruscino et al. 2008), acid-base balance status was still significantly rising to a more alkalotic state. It is plausible to suggest, therefore, if a longer period of recovery was employed, a more pronounced performance effect may have been observed compared to PLA. Moreover, this also suggests that re-dosing $\mathrm{NaHCO}_{3}$ following an initial fatiguing bout is not required, as acid-base balance increased well above baseline, despite no re-dosing of $\mathrm{NaHCO}_{3}$. These findings may be of importance to individuals who suffer from GI discomfort, as no instances were reported during recovery in the current study. Future research should, therefore, investigate the performance responses on repeated exercise following $\mathrm{NaHCO}_{3}$ ingestion with a longer period of recovery.

One participant presented an ergolytic effect in both $\mathrm{TT}_{1}$ and $\mathrm{TT}_{2}$ after ingestion of SBC3. This was likely due to the occurrence of severe GI discomfort (diarrhoea $=10$; aggregate score $=63$ ), as this participant still improved their performance in SBC2. These findings support the previous research, whereby ergolytic effects were observed in participants who suffered from severe GI discomfort following $0.3 \mathrm{~g} \mathrm{~kg}^{-1} \mathrm{BM} \mathrm{NaHCO}_{3}$ (Saunders et al. 2014; Froio de Araujo Dias et al. 2015). It is therefore important to monitor the GI discomfort responses following $\mathrm{NaHCO}_{3}$ ingestion on an individual basis, as those who display severe symptoms following SBC3 may instead benefit from ingesting SBC2. The use of this smaller dose, however, will be dependent on an improvement in performance still being observed compared to a placebo.

\section{Conclusion}

This study investigated the effects of $\mathrm{NaHCO}_{3}$ ingestion on repeated $4 \mathrm{~km}$ TT performance and acid-base balance recovery in acute moderate hypoxic conditions. Both amounts of $\mathrm{NaHCO}_{3}$ employed in this study ensured recovery of acid-base balance back to baseline or above within 20-40 min, whereas this was not achieved for PLA. For the first time, blunting of the acid-base balance stress during the initial bout of exercise, or a greater magnitude of acid-base balance recovery, has translated into improved subsequent high-intensity exercise performance following 
$\mathrm{NaHCO}_{3}$ ingestion in acute hypoxic conditions. The performance improvement was greater in SBC3, which is likely due to the greater alkalotic status of acid-base balance both prior to $\mathrm{TT}_{1}$, and during recovery compared to $\mathrm{SBC} 2$ and PLA. The onset of GI discomfort was an issue with SBC3, however, and one participant displayed an ergolytic effect on performance following this dose. Individuals should, therefore, employ SBC3 to improve performance in acute hypoxic conditions, only if severe GI discomfort does not occur.

Author contributions Conception or design of the work: the original conception of the work was conducted by LG. Data collection: data were collected by LG. Data analysis and interpretation: completed by LG. Drafting the article: completed by LG. Critical revision of the article: all authors (DB, SD, SAS, and LRM) on the manuscript contributed. Final approval of the version to be published: this was sought from all authors (DB, SD, SAS, and LRM).

Funding No sources of funding were used to conduct this study or prepare this manuscript.

\section{Compliance with ethical standards}

Conflict of interest LA Gough, SK Deb, D Brown, SA Sparks, and LR McNaughton have no conflicts of interest that are directly relevant to the content of this article.

Open Access This article is distributed under the terms of the Creative Commons Attribution 4.0 International License (http://creativeco mmons.org/licenses/by/4.0/), which permits unrestricted use, distribution, and reproduction in any medium, provided you give appropriate credit to the original author(s) and the source, provide a link to the Creative Commons license, and indicate if changes were made.

\section{References}

Allen DG, Lamb GD, Westerblad H (2008) Impaired calcium release during fatigue. J Appl Physiol 104(1):296-305

Al-Nawaiseh AM, Pritchett RC, Bishop PA (2016) Enhancing shortterm recovery after high-intensity anaerobic exercise. J Strength Cond Res 30(2):320-325

Baguet A, Harmen R, Andries P, Inge E, Stefanie C, Eric A, Wim D (2009) Carnosine loading and washout in human skeletal muscles. J Appl Physiol 106(3):837-842

Barnett A (2006) Using recovery modalities between training sessions in elite athletes does it help? Sports Med 36(9):781-786

Batterham AM, Hopkins WG (2006) Making meaningful inferences about magnitudes. Int J Sports Physiol Perform 1(1):50-57

Bonaventura JM, Sharpe K, Knight E, Fuller KL, Tanner RK, Gore CJ (2015) Reliability and accuracy of six hand-held blood lactate analysers. J Sports Sci Med 14(1):203

Cairns SP (2006) Lactic acid and exercise performance: culprit or friend? Sports Med 36(4):279-291

Cairns SP, Lindinger MI (2008) Do multiple ionic interactions contribute to skeletal muscle fatigue? J Physiol 586(17):4039-4054

Callahan MJ, Parr EB, Hawley JA, Burke LM (2017) Single and combined effects of beetroot crystals and sodium bicarbonate on 4-km cycling time trial performance. Int J Sport Nutr Exerc Metab 27(3):271-278
Cohen J (1988) Statistical power analysis for the behavioural sciences. Lawrence Erlbaum Associates, Hillsdale

De Pauw K, Roelands B, Cheung SS, De Geus B, Rietjens G, Meeusen R (2013) Guidelines to classify subject groups in sport-science research. Int J Sports Physiol Perform 8(2):111-122

Durkalec-Michalski K, Zawieja EE, Podgórski T, Łoniewski I, Zawieja BE, Warzybok M, Jeszka J (2018) The effect of chronic progressive-dose sodium bicarbonate ingestion on CrossFit-like performance: a double-blind, randomized cross-over trial. PLoS One 13(5): 0197480

Egger F, Meyer T, Such U, Hecksteden A (2014) Effects of sodium bicarbonate on high-intensity endurance performance in cyclists: a double-blind, randomized cross-over trial. PLoS One 9(12):e114729

Fitts RH (2016) The role of acidosis in fatigue. Med Sci Sports Exerc 48(11):2335-2338

Froio de Araujo Dias G, Da Eira Silva V, De Salles Painelli V, Sale C, Giannini Artioli G, Gualano B, Saunders B (2015) Consistencies in responses to sodium bicarbonate supplementation: a randomised, repeated measures, counterbalanced and double-blind study. PLoS One 10(11):e0143086

Gough LA, Rimmer S, Osler CJ, Higgins MF (2017a) Ingestion of sodium bicarbonate $\left(\mathrm{NaHCO}_{3}\right)$ following a fatiguing bout of exercise accelerates postexercise acid-base balance recovery and improves subsequent high-intensity cycling time to exhaustion. Int J Sport Nutr Exerc Metab 27(5):429-438

Gough LA, Deb SK, Sparks SA, McNaughton LR (2017b) The reproducibility of blood acid base responses in male collegiate athletes following individualised doses of sodium bicarbonate: a randomised controlled crossover study. Sports Med 47(10):2117-2127

Gough LA, Sanjoy K, Deb S, Sparks SA, McNaughton LR (2017c) Sodium bicarbonate improves $4 \mathrm{~km}$ time trial cycling performance when individualised to time to peak blood bicarbonate in trained male cyclists. J Sports Sci 36(15):1705-1712

Granier P, Dubouchaud H, Mercier B, Mercier J, Ahmaidi S, Préfaut C (1996) Lactate uptake by forearm skeletal muscles during repeated periods of short-term intense leg exercise in humans. Eur J Appl Physiol Occup Physiol 72(3):209-214

Hollidge-Horvat MG, Parolin ML, Wong D, Jones NL, Heigenhauser GJ (1999) Effect of induced metabolic acidosis on human skeletal muscle metabolism during exercise. Am J Physiol 277(4):647-658

Korzeniewski B, Zoladz JA (2002) Influence of rapid changes in cytosolic $\mathrm{pH}$ on oxidative phosphorylation in skeletal muscle: theoretical studies. Biochem J 365(1):249-258

Lloyd P (2004) Strong ion calculator - a practical bedside application of modern quantitative acid-base physiology. Crit Care Resusc 6(4):285-294

Lopes-Silva JP, Da Silva Santos JF, Artioli GG, Loturco I, Abbiss C, Franchini E (2018) Sodium bicarbonate ingestion increases glycolytic contribution and improves performance during simulated taekwondo combat. Eur J Sport Sci 18(3):1-10

Monedero J, Donne (2000) Effect of recovery interventions on lactate removal and subsequent performance. Int J Sports Med 21(8):593-597

Percival ME, Martin BJ, Gillen JB, Skelly LE, Macinnis MJ, Green AE, Tarnopolsky MA, Gibala MJ (2015) Sodium bicarbonate ingestion augments the increase in PGC- $1 \alpha$ mRNA expression during recovery from intense interval exercise in human skeletal muscle. J Appl Physiol 119(11):1303-1312

Pierce EF, Eastman NW, Hammer WH, Lynn TD (1992) Effect of induced alkalosis on swimming time trials. J Sports Sci 10(3):255-259

Pruscino CL, Ross MLR, Gregory JR, Savage B, Flanagan TR (2008) Effects of sodium bicarbonate, caffeine, and their combination 
on repeated 200-m freestyle performance. Int J Sport Nutr Exerc Metab 18(2):116-130

Pyne DB, Boston T, Martin DT, Logan A (2000) Evaluation of the Lactate Pro blood lactate analyser. Eur J Appl Physiol 82(1-2):112-116

Robergs R, Hutchinson K, Hendee S, Madden S, Siegler J (2005) Influence of pre-exercise acidosis and alkalosis on the kinetics of acidbase recovery following intense exercise. Int J Sport Nutr Exerc Metab 15(1):59-74

Sahlin K, Tonkonogi M, Söderlund K (1998) Energy supply and muscle fatigue in humans. Acta Physiol Scand 162(3):261-266

Saunders B, Sale C, Harris RC, Sunderland C (2014) Sodium bicarbonate and high-intensity-cycling capacity: variability in responses. Int J Sports Physiol Perform 9(4):627-632

Scofield KL, Hecht S (2012) Bone health in endurance athletes: runners, cyclists, and swimmers. Curr Sports Med Rep 11(6):328-334

Sebastian A, Harris ST, Ottaway JH, Todd KM, Morris Jr RC (1994) Improved mineral balance and skeletal metabolism in postmenopausal women treated with potassium bicarbonate. N Engl J Med 330(25):1776-1781

Sostaric SM, Skinner SL, Brown MJ, Sangkabutra T, Medved I, Medley T, McKenna MJ (2006) Alkalosis increases muscle $\mathrm{K}^{+}$release, but lowers plasma $\left[\mathrm{K}^{+}\right]$and delays fatigue during dynamic forearm exercise. J Physiol 570(1):185-205

Swinton PA, Hemingway BS, Saunders B, Gualano B, Dolan E (2018) A statistical framework to interpret individual response to intervention: paving the way for personalized nutrition and exercise prescription. Front Nutr 5:41

Tenforde AS, Carlson JL, Chang A, Sainani KL, Shultz R, Kim JH, Fredericson M (2017) Association of the female athlete triad risk assessment stratification to the development of bone stress injuries in collegiate athletes. Am J Sports Med 45(2):302-310

Ward R, Bridge CA, McNaughton LR, Sparks SA (2016) The effect of acute taurine ingestion on 4-km time trial performance in trained cyclists. Amino Acids 48(11):2581-2587

Westerblad H (2016) Acidosis is not a significant cause of skeletal muscle fatigue. Med Sci Sports Exerc 48(11):2339-2342

Wiederkehr M, Krapf R (2001) Metabolic and endocrine effects of metabolic acidosis in humans. Swiss Med Wkly 131(9-10):127-132

Zabala M, Requena B, Sánchez-muñoz C, González-Badillo JJ, García I, Ööpik V, Pääsuke M (2008) Effects of sodium bicarbonate ingestion on performance and perceptual responses in a laboratory-simulated bmx cycling qualification series. J Strength Cond Res 22(5):1645-1653

Zabala M, Peinado AB, Calderón FJ, Sampedro J, Castillo MJ, Benito PJ (2011) Bicarbonate ingestion has no ergogenic effect on consecutive all out sprint tests in BMX elite cyclists. Eur J Appl Physiol 111(12):3127-3134

Zoladz JA, Szkutnik Z, Duda K, Majerczak J, Korzeniewski B (2005) Preexercise metabolic alkalosis induced via bicarbonate ingestion accelerates $V \mathrm{O}_{2}$ kinetics at the onset of a high-power-output exercise in humans. J Appl Physiol 98(3):895-904 